\title{
STIMULATION OF GROWTH AND OIL PRODUCTION IN CUMIN PLANT
}

\author{
Hanan M.H. Ali and Hala F. Mohammed \\ Medicinal and Aromatic Plants Research Department, Horticulture Research Institute, Agricultural \\ Research Center, Giza, Egypt
} ABSTRACT: A pot experiment was carried out during two successive
seasons (2017/ 2018 and 2018/2019) at Medicinal and Aromatic Plants
Research Department in Dokki. The aim of this work was to study the
effect of foliar application of phenylalanine (Phe) and $p$-nitro
phenylacetic acid (PNPAA) each of them alone at (0,50, 100 and 150
ppm) on cumin (Cuminum cyminum L.) plant growth, fruits yield,
volatile oil production and its major chemical constituents. In general
results indicated that, the foliar application of phenylalanine or
p-nitrophenylacetic acid significantly increased vegetative growth
expressed as (plant height, number of branches per plant) and produced
higher fruits yield (g)/plant as well as volatile oil percentage and oil
yield compared with control in the two seasons. Moreover, the highest
values were obtained from phenylalanine or p-nitrophenylacetic acid at
150 ppm. Cumin plants showed more effective response to
-nitrophenylacetic acid (PNPAA) than phenylalanine (Phe). As for

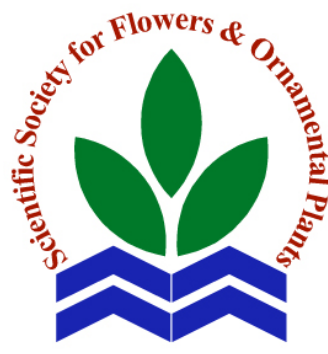

Scientific J. Flowers \& GLC analysis, the results showed that in general the highest percentage

Ornamental Plants, 7(4):501-512 (2020).

Received:

$14 / 11 / 2020$

Accepted:

$30 / 11 / 2020$

of $p$-menth-1-en7-ol and cumin aldehyde ( $p$-isopropylbenzaldehyde) the main constituents in the volatile oil achieved with the treatment $p$-nitrophenylacetic acid at $150 \mathrm{ppm}$. The high concentration of phenylalanine and $p$-nitrophenylacetic acid (150 ppm) had significant increments in total phenols, total flavonoids and antioxidant activity compared with control. There was a significant increase in phenylalanine ammonia-lyase (PAL) activity compared to control. Also, there was an increment in IAA, GA3 and low level of ABA. It was observed that $p$-nitrophenylacetic acid $(150 \mathrm{ppm})$ was superior to phenylalanine $(150 \mathrm{ppm})$ in all afore mentioned characters.

Key words: Cumin, phenylalanine, $p$-nitrophenylacetic acid, fruits yield, oil constituents.

\section{INTRODUCTION}

Cumin (Cuminum cyminum L.) is an annual important plant belongs to Apiaceae family. The fruits are carminative (Bettaieb et al., 2012 and Hashemian et al., 2013) aromatic, stomachic, stimulant. Also, the fruits of cumin are used extensively as a spice and flavoring for culinary purposes in many cuisines. The volatile oil is responsible for characteristic cumin odor. This odor and flavor are principally attributed to the aldehydes present. Cuminaldehyde ( $p$ - isopropylbenzaldehyde) is the major component in the volatile oil of cumin fruits. In addition, it can stimulate different biological effects such as antimicrobial, antiinflammatory, antioxidant and anticancer (Oroojalian et al., 2010).

Phenylalanine is an essential amino acid that plays an important role in the interconnection between primary and secondary metabolism in plants. Phenylalanine is used as a protein building block and it is also as a precursor for 
numerous plant compounds that are necessary for plant growth, development, reproduction and defense against different types of stresses (Pascual et al., 2016).

Phenylalanine provide plant with important precursors of aromatic secondary metabolites such as alkaloids, flavonoids, lignins, and aromatic antibiotics. Many of these compounds are bioactive as well as playing important roles in plant defense against biotic and abiotic stresses and environmental interactions (Hamberger et al., 2006; Maeda and Dudareva, 2012). The application of phenylalanine during vegetative and flowering stages caused an enhancement in plant growth (Habba, 2003 and Reham et al., 2016). Small and Morris (1990) reported that phenylacetic acid stimulates the elongation of coleoptile segments of oats (Avena sativa) and intermodal of beans (Phaseolus vulgaris).

Phenylalanine ammonia-lyase (PAL) is one of the most important enzymes that plays important role in regulation phenylpropanoid biosynthesis in plants and growth response. It catalyzes the first step of the conversion of L-phenylalanine to cinnamic acid, linking primary metabolism with secondary metabolism. This step is significant for metabolic engineering and hyper-expression of the major phenylpropanoid, methyl chavicol (Wang et al., 2014). PAL is controlling primary metabolism to secondary metabolism in the phenylpropanoid metabolic pathway. This metabolic pathway not only produces concentrated tannins, flavonoids and lignin, but also produces less-studied benzene compounds and phenolic glycosides.

Recent research has established that $\mathrm{NO}_{2}$ is a phytohormone, the exogenous application of $\mathrm{NO}_{2}$ positively regulates plant growth. Also, $\mathrm{NO}_{2}$ is immigrant or departure group with the ability to replace (Takahashi and Morikawa, 2014).

The goal of this work was to study the effect of foliar application of different concentrations of phenylalanine (Phe) and $p$ - nitrophenylacetic acid on growth and volatile oil production of cumin plants.

\section{MATERIALS AND METHODS}

This study was carried out during two successive seasons 2017/2018 and 2018/2019 at Medicinal and Aromatic plants Research Department, Dokki, Egypt.

\section{Plant materials and procedures:}

The fruits of cumin (Cuminum cyminum L.) were obtained from the Experimental Farm of Medicinal and Aromatic Plants Research Department, El-Kanater El-Khairia and sown on $15^{\text {th }}$ November in the two seasons.

\section{Chemical fertilizers:}

Chemical fertilizers (NPK) were added as ammonium sulphate $(20.6 \% \mathrm{~N})$, calcium superphosphate $\left(15.5 \% \mathrm{P}_{2} \mathrm{O}_{5}\right)$ and potassium sulphate $\left(48 \% \quad \mathrm{~K}_{2} \mathrm{O}\right)$ at the recommended level in three doses. The $1^{\text {st }}$ one (all phosphorous amount) was added during soil preparation, the rest (NK) doses were applied in two equal splits, after 30 and 60 days from sowing.

\section{Treatments:}

Foliar application of phenylalanine and $p$-nitrophenylacetic acid each of them solely were done four times. The first dose was given 30 days after sowing and was repeated three times after 15 days interval, seven treatments were conducted as follow: (1) control (untreated plants); (2), (3) and (4) phenylalanine (Phe) at 50, 100 and $150 \mathrm{ppm}$, respectively; (5), (6) and (7) $p$ nitrophenylacetic acid (PNPAA) at 50, 100 and $150 \mathrm{ppm}$, respectively.

\section{Data recorded:}

The following data were recorded:

1. Plant height $(\mathrm{cm})$.

2. Number of branches/pant.

3. Fruits yield (g)/plant.

4. Volatile oil percentage $(\% \mathrm{v} / \mathrm{w})$ was determined according to (British Pharmacopeia, 1963). 
5. Volatile oil yield ( $\mathrm{ml}) /$ plant.

6. The main constituents of cumin fruits volatile oil were determined by subjecting oil samples (of the $2^{\text {nd }}$ season to gas liquid chromatography (GLC) analysis as recommended by (Hoftman, 1967 and Bunzen, 1969).

7. Determination of total phenols: total phenols content was determined in fruits by using Folin- Ciocalteu assay, as described by (Amin et al., 2006).

8. Determination of total flavonoids content: total flavonoids content was determined in fruits by using previously reported method by (Chang et al., 2002).

9. Antioxidant activities: the antioxidant activity (in percent) was evaluated in fruits by 1, 1-diphenyl-2-picrylhydrazyl radical scavenging method according to the procedure of (Chen et al., 2008).

10. Phenylalanine ammonia-lyase (PAL) activity: PAL activity was determined in fresh herb. The crude enzyme extract was assayed by using the methods of (Zucker,1965; McCallum and Walker 1990).

11. Determination of Plant hormones: plant hormones were determined in fresh herb according to the method described by
(Horemans et al., 1984).

\section{Layout of experiment:}

The experiment layout was designed in complete randomized blocks included seven treatments each treatment was replicated three times and every replicate consisted of nine pots. The recorded data were statistically analyzed according to (Snedecor and Cochran, 1980).

\section{RESULTS AND DISCUSSION}

Effect of phenylalanine and $p$ nitrophenylacetic acid on vegetative growth:

Data in Table (1) showed that, all concentrations of phenylalanine (Phe) and $p$ nitrophenylacetic acid each of them alone significantly increased plant height and number of branches/plant as compared to control in the two seasons. The best results were obtained from phenylalanine (Phe) at $150 \mathrm{ppm}$ which gave 22.24 and $22.60(\mathrm{~cm})$ plant height and 5.78 and 6.08 branches/plant in both seasons. These results are in agreement with the findings of (Gamal-El-Din et al., 1997) they mentioned that phenylalanine treatment increased vegetative growth of lemon grass.

The highest values were recorded in case of those plants treated with $p$-nitro phenyl acetic acid at $150 \mathrm{ppm}$, the values were

Table 1. Effect of phenylalanine and $p$-nitrophenylacetic acid on vegetative growth of cumin plants during $2017 / 2018$ and $2018 / 2019$ seasons.

\begin{tabular}{lcccc}
\hline \multicolumn{1}{c}{ Treatments } & \multicolumn{4}{c}{ Growth characters } \\
& $\begin{array}{c}\mathbf{1}^{\text {st }} \text { season } \\
\text { Plant height } \\
\text { (cm) }\end{array}$ & $\begin{array}{c}\text { Number of } \\
\text { branches /plant }\end{array}$ & $\begin{array}{c}\text { Plant height } \\
\text { (cm) }\end{array}$ & $\begin{array}{c}\text { season } \\
\text { Number of } \\
\text { branches /plant }\end{array}$ \\
\hline Control & 17.50 & 3.33 & 17.82 & 3.67 \\
Phenylalanine (Phe) at 50ppm & 19.13 & 3.89 & 19.53 & 4.44 \\
Phenylalanine (Phe) at 100ppm & 20.87 & 4.67 & 21.92 & 5.00 \\
Phenylalanine (Phe) at 150ppm & 22.24 & 5.78 & 22.60 & 6.08 \\
p-nitrophenylacetic acid (PNPAA) at 50 ppm & 23.69 & 6.33 & 25.18 & 6.44 \\
p-nitrophenylacetic acid (PNPAA) at $\mathbf{1 0 0} \mathbf{~ p p m}$ & 26.83 & 7.11 & 28.47 & 7.33 \\
p-nitrophenylacetic acid (PNPAA) at $\mathbf{1 5 0} \mathbf{~ p p m}$ & 28.89 & 7.44 & 29.88 & 7.56 \\
L.S.D.at 5\% & 1.35 & 0.50 & 0.90 & 0.28 \\
\hline
\end{tabular}


28.89 and $29.88(\mathrm{~cm})$ for plant height and 7.44 and 7.56 for branches/plant in the two seasons. These results may be attributed to both nitro $\left(\mathrm{NO}_{2}\right)$ group and phenylacetic acid are phytohormones which increased shoot biomass (Jin et al., 2009).

Effect of phenylalanine and $p$ nitrophenylacetic acid on fruits yield (g)/plant:

All concentrations of phenylalanine (Phe) or $p$-nitrophenylacetic acids; 50, 100 and $150 \mathrm{ppm}$ significantly increased fruits yield per plant as compared to control in both seasons. High fruits yield per plant 3.07 and $3.13(\mathrm{~g}) /$ plant were recorded in the plant received phenylalanine (Phe) at $150 \mathrm{ppm}$ in $1^{\text {st }}$ and $2^{\text {nd }}$ seasons, respectively Table (2). These results may be due to the beneficial effect of amino acids which facilitate nutrients absorption by the roots. Khalilzadeh et al. (2012) mentioned that, amino acids play essential role in plant metabolism and protein assimilation which are necessary for cell formation. Moreover, amino acids regulate photosynthesis and plant production.

The most effective treatment in this concern was $p$-nitrophenylacetic acid (PNPAA) at $150 \mathrm{ppm}$ which gave 3.26 and $3.32 \mathrm{~g}$ fruits/plant in the $1^{\text {st }}$ and $2^{\text {nd }}$ seasons, respectively. Such effect may be due to the regulation of the growth and reproductive of plants by exogenous nitro $\left(\mathrm{NO}_{2}\right)$ group (Santner and Estelle, 2009). Also, phenylacetic acid (PAA) is a natural auxin has the ability to regulate cell division, cell growth, ethylene biosynthesis, root development, leaf formation, apical dominance and differentiation of vascular tissues and fruit setting (Finet and Jaillais, 2012).

Effect of phenylalanine and $p$ nitrophenylacetic acid on volatile oil production:

Volatile oil percentage and its yield ml/plant:

It could be noticed that the application of phenylalanine (Phe) or $p$-nitrophenylacetic acid (PNPAA) at $150 \mathrm{ppm}$ showed a significant increase in volatile oil percentage and yield over control in the two seasons Table (3). The best results were obtained from plants treated with $p$-nitrophenyl acetic acid (PNPAA) at $150 \mathrm{ppm}$, giving 4.96 and $5.02 \%$ and yield 0.17 and $0.18 \mathrm{ml} /$ plant in both seasons. However, phenylalanine at 150 ppm occupied the second rank. Similar results were observed by (Talaat and Youssef, 2002), they mentioned that foliar application of amino acids significantly increased volatile oil percentage and yield on basil plants.

Table 2. Effect of phenylalanine and $p$-nitrophenylacetic acid on fruits yield of cumin plants during $2017 / 2018$ and $2018 / 2019$ seasons.

\begin{tabular}{lcc}
\hline \multicolumn{1}{c}{ Treatments } & \multicolumn{2}{c}{ Fruits yield (g) / plant } \\
& $\mathbf{1}^{\text {st }}$ season & $\mathbf{2}^{\text {nd }}$ season \\
\hline Control & 2.57 & 2.65 \\
Phenylalanine (Phe) at $\mathbf{5 0} \mathbf{~ p p m}$ & 2.78 & 2.81 \\
Phenylalanine (Phe) at $\mathbf{1 0 0} \mathbf{~ p p m}$ & 2.91 & 2.96 \\
Phenylalanine (Phe) at $\mathbf{1 5 0} \mathbf{~ p p m}$ & 3.07 & 3.13 \\
$\boldsymbol{p}$-nitrophenylacetic acid (PNPAA) at $\mathbf{5 0} \mathbf{~ p p m}$ & 3.13 & 3.20 \\
$\boldsymbol{p}$-nitrophenylacetic acid (PNPAA) at $\mathbf{1 0 0} \mathbf{~ p p m}$ & 3.22 & 3.25 \\
$\boldsymbol{p}$-nitrophenylacetic acid (PNPAA) at $\mathbf{1 5 0} \mathbf{~ p p m}$ & 3.26 & 3.32 \\
L.S.D.at 5\% & 0.026 & 0.042 \\
\end{tabular}


Table 3. Effect of phenylalanine and $p$-nitrophenylacetic on volatile oil production of cumin plants during 2017/ 2018 and $2018 / 2019$ seasons.

\begin{tabular}{lcccc}
\hline \multicolumn{1}{c}{ Treatments } & \multicolumn{2}{c}{$\mathbf{1}^{\text {st }}$ season } & \multicolumn{2}{c}{$\mathbf{2}^{\text {nd }}$ season } \\
& $\begin{array}{c}\text { Volatile oil } \\
\text { percentage }\end{array}$ & $\begin{array}{c}\text { Volatile oil } \\
\text { yield (ml) } \\
\text { /plant }\end{array}$ & $\begin{array}{c}\text { Volatile oil } \\
\text { percentage }\end{array}$ & $\begin{array}{c}\text { Volatile oil } \\
\text { yield (ml) } \\
\text { /plant }\end{array}$ \\
\hline Control & 4.01 & 0.10 & 4.09 & 0.11 \\
Phenylalanine (Phe) at 50 ppm & 4.17 & 0.12 & 4.25 & 0.13 \\
Phenylalanine (Phe) at 100ppm & 4.36 & 0.13 & 4.49 & 0.14 \\
Phenylalanine (Phe) at 150ppm & 4.52 & 0.14 & 4.64 & 0.15 \\
p-nitrophenylacetic acid (PNPAA) at 50 ppm & 4.69 & 0.15 & 4.74 & 0.16 \\
p-nitrophenylacetic acid (PNPAA) at 100 ppm & 4.84 & 0.16 & 4.86 & 0.17 \\
p-nitrophenylacetic acid (PNPAA) at 150 ppm & 4.96 & 0.17 & 5.02 & 0.18 \\
L.S.D.at 5\% & 0.05 & 0.01 & 0.03 & 0.01 \\
\hline
\end{tabular}

From the above results it could be concluded that, $p$-nitrophenylacetic acid (PNPAA) was more effective than phenylalanine (Phe) regarding volatile oil production as well as all growth characters. This effectiveness of $p$-nitrophenylacetic acid (PNPAA) than phenylalanine (Phe) may be attributed to nitro $\left(\mathrm{NO}_{2}\right)$ group which is considered as phytohormone so, positively regulates and improves growth of plant (Takahashi and Morikawa, 2014) also, phenylacetic acid (PAA) is a natural auxin plays a central role in plant growth and reproductive (Schneider et al., 1985). ELZefzafy et al., (2016) reported that foliar application of phenylalanine significantly promoted the growth and volatile oil production.

Effect of phenylalanine and $p$ nitrophenylacetic acid on chemical composition of volatile oil:

Data presented in Table (4) showed that $p$-menth-1-en7-ol (ranged from 43.23 and $45.29 \%)$ and cuminaldehyde ( $p$ isopropylbenzaldehyde ranged from 19.45 to $33.11 \%$ ) were the main components of volatile oil.

Concerning the effect of phenylalanine (Phe), data indicated that all treatments increased cuminaldehyde ( $p$-isopropylbenzaldehyde) percentage in volatile oil. Increasing the concentration of phenylalanine (Phe) gradually increased cuminaldehyde percentage as compared to control. In general, treating cumin plants with $p$-nitrophenyl acetic acid (PNPAA) at 150 ppm gave the highest values of $p$-menth1-en7-ol $(45.29 \%)$ and cuminaldehyde $(33.11 \%)$, respectively compared with control (untreated plants). The most effective treatment was $p$-nitrophenylacetic acid (PNPAA) at $150 \mathrm{ppm}$ in this concern.

These results may be due to the activity of phenylalanine ammonia-lyase (PAL), the first enzyme of phenylpropanoid pathway. It was found to be directly involved in 2hydroxy-4-methoxybenzaldehyde biosynthesis, which route of another fragrant cuminaldehyde ( $p$-isopropylbenzaldehyde) (Giridhar et al., 2004). Elicitation is a standard method to enhance the phenolic metabolism in excised plant tissue, organs and cell cultures (Kneer et al.,1999). In another report, correlation of shikimate pathway with 2-hydroxy-4-methoxybenzaldehyde biosynthesis has been established considering the possible biosynthesis path in yeast extract-elicited Hemidesmus indicus roots (Kundu et al., 2012). An evidence of $C_{2}$ side -chain cleavage activity was also found in Hemidesmus indicus roots that catalyzed the $\mathrm{C}_{2}$ side - chain cleavage the $\mathrm{C}_{6-} \mathrm{C}_{1}$ compound (4-hydroxybenzaldehyde). This phenomenon supports the proposed pathway of vanillin 
Table 4. Effect of phenylalanine and p-nitrophenylacetic acid on GLC analysis of volatile oil of cumin fruits during 2018 /2019 season.

\begin{tabular}{cccccccc}
\hline Components & Control & $\begin{array}{c}\text { Phe } \\
\mathbf{5 0} \mathbf{~ p p m}\end{array}$ & $\begin{array}{c}\text { Phe } \\
\mathbf{1 0 0} \mathbf{~ p p m}\end{array}$ & $\begin{array}{c}\text { Treatments } \\
\mathbf{1 5 0} \mathbf{~ p p m}\end{array}$ & $\begin{array}{c}\text { PNPAA } \\
\mathbf{5 0} \mathbf{~ p m}\end{array}$ & $\begin{array}{c}\text { PNPAA } \\
\mathbf{1 0 0} \mathbf{~ p p m}\end{array}$ & $\begin{array}{c}\text { PNPAA } \\
\mathbf{1 5 0} \mathbf{~ p p m}\end{array}$ \\
\hline $\boldsymbol{\alpha}$-Thujene & 0.80 & 0.86 & 0.70 & 0.92 & 0.90 & - & - \\
$\boldsymbol{\beta}$-pinene & 14.40 & 12.91 & 12.83 & 16.34 & 15.46 & 12.11 & 8.36 \\
Myrcene & 13.20 & 14.14 & 14.26 & 13.25 & 13.00 & 11.02 & 8.21 \\
$\boldsymbol{\alpha}$-phyllandrene & 6.09 & 1.70 & 5.02 & 0.40 & 5.09 & 3.60 & 3.84 \\
$\boldsymbol{p}$-cymene & 0.24 & 5.23 & 0.28 & 5.21 & 1.21 & - & - \\
$\boldsymbol{\gamma}$-Terpinene & 0.71 & 0.50 & 0.15 & 1.26 & 0.20 & - & - \\
Cuminaldehyde & 19.45 & 19.90 & 20.17 & 21.15 & 21.30 & 23.01 & 33.11 \\
$\boldsymbol{p}$-menth-1-en7-ol & 43.23 & 42.31 & 43.38 & 39.05 & 40.42 & 49.08 & 45.29 \\
$\boldsymbol{\beta}$ - caryophylene & 0.62 & 0.46 & 0.27 & 0.48 & 0.35 & - & - \\
Unknown & 1.50 & 1.99 & 2.94 & 1.94 & 2.07 & 1.18 & 1.19 \\
\hline
\end{tabular}

biosynthesis through the formation of hydroxybenzaldehyde by a chain-cleaving mechanism. Inhibition of shikimate pathway decreased this $\mathrm{C}_{2}$ chain-cleaving enzyme, which also emphasizes that shikimate pathway modulates the downstream enzymes involved in 2-hydroxy-4-methoxybenzaldehyde biosynthesis. There are no reports available on the downstream enzymes of 2-hydroxy-4-methoxybenzaldehyde biosynthesis after $\mathrm{C}_{2}$ sidechain shortening.

Therefore, there is a scientific trials need for much research in the future. This information establishes cuminaldehydes promising group of compounds with simple, small structure from pharmacological and industrial perspective. Therefore, it is important to study the biosynthetic routes of cuminaldehydes characterization of involved enzymes. It will be useful for metabolic engineering of the cuminaldehyde contents in plants for industrial purposes. The final product of shikimate pathway, chorismate, is converted to prephenate, a branch point in phenylalanine (Phe) synthesis, by a chorismatemutase (Lee et al.,1995; Herriman and Weaver,1999). Some species are capable of synthesizing an unusual variant of Lphenylalanine, the amino derivative L- $p$ aminophenylalanine ( L-PAPA), but utilizing the PABA ( $p$-aminobenzoic acid) precursor
4- amino-4-deoxychorismic acid instead of chorismic acid. Thus, amino derivatives of prephenic acid and pyruvic acid are elaborated. Phenylpyruvate is subsequently converted to Phe by a phenylpyruvate aminotransferase (Tzin et al., 2009; Maeda et al., 2010 and Yoo et al., 2013). It has been suggested that PAA (phenylacetic acid) biosynthesis in plants also occurs via phenylpyruvate (Taylor and Wightman, 1987). It has further been proposed that the enzymes responsible for IAA biosynthesis are involved in the conversion of Phe to PAA (Sugawara et al., 2015).Although it should be noted that transamination is a reversible process (Jensen and $\mathrm{Gu}, 1996$ ). Interestingly, the aminotransferases discussed in relation to Phe biosynthesis in Petunia hybrida (Yoo et al., 2013). Results presented here supported the theory that PAA is derived from phenylpyruvate as suggested by (Sugawara et al., 2015). We were unable to detect the endogenous species of phenylacetic acid in our feeding studies. Introduction of feedback-insensitive $p$ nitrophenylacetic acid (PNPAA) also led to increased production of many shikimatederived metabolites, including plant benzaldehyde. In brief, the importance of cuminaldehyde ( $p$-iso-propylbenzaldehyde) in natural products research cannot be overlooked as they have functional and 
potential roles in medicine, agriculture and industry. Therefore, up to date knowledge is required for further progress in $p$-isopropylbenzaldehyde research. In this paper, we discuss the available scientific literature regarding the occurrence of cuminaldehyde in plants as natural products, medicinal properties and biosynthesis. Thus, we aim to compile information on the research in this field and review the latest advances in the fragrant $p$-isopropylbenzaldehyde research.

In general, biosynthesis of benzenoids from phenylalanine requires shortening of the carbon skeleton side chain by a $\mathrm{C}_{2}$ unit which can potentially occur via either the $\beta$ oxidative pathway or non-oxidatively (Boatright et al., 2004). Experiments with stable isotope-labeled precursors in tobacco leaves (Ribnicky et al., 1998) reported that benzoic acid is derived from phenylalanine converted to cinnamic acid via $\beta$ oxidative pathway first product benzoyl CoA, which can be hydrolyzed by thioesterase to free benzoic acid. In contrast, labeling experiments together with initial enzyme characterization, in Hypericuman dosaemum cell cultures (Ahmed et al., 2002) confirmed the existence of a pathway of non-oxidative conversion of cinnamic acid to benzaldehyde subsequent formation of benzoic acid, which can be converted to benzoyl CoA (Beuerle and Pichersky, 2002). In vivo isotope labeling and metabolic flux analysis of the benzenoid network in Petunia hybrida flowers revealed that both pathways yield benzenoid compounds and that benzylbenzoate is an intermediate between L- phenylalanine and benzoic acid (Boatright et al., 2004). Transgenic Petunia hybrida plants were generated in which expression of benzoyl CoA: phenylethanol/benzyl alcohol benzoyltransferase (BPBT), the gene encoding the enzyme that uses benzoyl CoA and benzyl alcohol to make benzylbenzoate formation decreased endogenous pool of benzyl acid and methyl benzoate emission but increased emission of benzylalcohol and benzylaldehyde, confirming the contribution of benzylbenzoate to benzoic acid formation (Orlova et al.,2006).
Data in Table (5) indicated that high concentration of phenylalanine (Phe) 150 ppm significantly increased total phenols, total flavonoids and antioxidant activity as compared to control. Total phenolic content expressed as mg Gallic acid Equivalent $\mathrm{GAE} / \mathrm{g}$ fruits and flavonoids content expressed as mg Querctine Equivalent (QE)/g fruits, the enzyme activity was referred to as fresh weight (U/g FW). Maximum phenolic content was in plants treated with (PNPAA) at $150 \mathrm{ppm}$. The value was $28.5 \mathrm{mg} \mathrm{GAE} / \mathrm{g}$ fruits. The same results were observed in total flavonoids content where maximum was $16.29 \mathrm{mg} \mathrm{QE} / \mathrm{g}$ fruits.

Data showed that cumin fruits had potent antioxidant capable of scavenging DPPH free radicals. The best results were obtained from $p$-nitrophenylacetic acid at $150 \mathrm{ppm}$ which gave $86.09 \%$. The results are in agreement with (Gamal EL-Din and Abd ElWahed, 2005) reported that the effects of foliar application of phenylalanine on chamomile (Matricaria chamomilla L., Rausch.) led to significant increases in total phenols.

Also, data in Table (5) revealed that there was a significant increase in Phenylalanine ammonialyase (PAL) activity compared with the control in cumin plants treated with phenylalanine (Phe) and $p$ nitrophenylacetic acid (PNPAA) at concentrations 50,100 and $150 \mathrm{ppm}$. These results were in agreement with (Bahadur et al., 2012) who reported that pea leaves treated with different concentrations (100 and $150 \mathrm{ppm}$ ) of phenylalanine (Phe) caused increment in PAL activity in compared with control.

Data represented in Table (6) showed increments in gibberellin $\left(\mathrm{GA}_{3}\right)$ and indole acetic acid (IAA) in plants treated with phenylalanine and PNPAA. The highest concentration of $\mathrm{GA}_{3}(5.82 \mathrm{mg} / 100 \mathrm{~g})$ and IAA $(1.05 \mathrm{mg} / 100 \mathrm{~g})$ were in plants treated with PNPAA at concentration of $150 \mathrm{ppm}$. A reduction in abscisic acid (ABA) level was concomitant with increments in $\mathrm{GA}_{3}$ and IAA estimated in plants treated with PNPAA 
Table 5. Effect of phenylalanine and $p$-nitrophenylacetic acid on total phenols, total flavonoids and antioxidant activity of cumin plants during 2018 /2019 season.

\begin{tabular}{lcccc}
\hline \multicolumn{1}{c}{ Treatments } & $\begin{array}{c}\text { Total phenols } \\
\text { (mg/g) }\end{array}$ & $\begin{array}{c}\text { Total } \\
\text { flavonoids } \\
\text { (mg/g) }\end{array}$ & $\begin{array}{c}\text { Antioxidants } \\
\mathbf{( \% )}\end{array}$ & $\begin{array}{c}\text { Enzyme } \\
\text { activity } \\
\text { (U/g FW) }\end{array}$ \\
\hline Control & 17.71 & 8.27 & 65.06 & 0.146 \\
Phenylalanine (Phe) at $\mathbf{5 0} \mathbf{~ p p m}$ & 19.97 & 10.12 & 67.03 & 0.168 \\
Phenylalanine (Phe) at $\mathbf{1 0 0} \mathbf{~ p p m}$ & 22.00 & 13.03 & 69.56 & 0.245 \\
Phenylalanine (Phe) at $\mathbf{1 5 0} \mathbf{~ p p m}$ & 23.72 & 13.85 & 72.30 & 0.288 \\
p-nitrophenylacetic acid (PNPAA) at 50 ppm & 25.46 & 14.82 & 77.17 & 0.325 \\
p- nitrophenylacetic acid (PNPAA) at 100 ppm & 26.45 & 15.15 & 81.40 & 0.351 \\
p-nitrophenylacetic acid (PNPAA) at $\mathbf{1 5 0} \mathbf{~ p p m}$ & 28.50 & 16.29 & 86.09 & 0.376 \\
L.S.D. at 5\% & 2.81 & 2.04 & 3.77 & 0.021 \\
\hline
\end{tabular}

Table 6. Effect of phenylalanine and $p$-nitrophenylacetic acid treatments on phytohormone contents (mg/100 g).

\begin{tabular}{llll}
\hline \multicolumn{1}{c}{ Treatments } & GA3 & IAA & ABA \\
\hline Control & 2.11 & 0.77 & 0.71 \\
Phenylalanine (Phe) at $\mathbf{5 0} \mathbf{~ p p m}$ & 3.22 & 0.82 & 0.65 \\
Phenylalanine (Phe) at $\mathbf{1 0 0} \mathbf{~ p p m}$ & 3.68 & 0.97 & 0.57 \\
Phenylalanine (Phe) at $\mathbf{1 5 0} \mathbf{~ p p m}$ & 4.04 & 1.01 & 0.45 \\
$\boldsymbol{P}$-nitrophenylacetic acid (PNPAA) at $\mathbf{5 0} \mathbf{~ p p m}$ & 5.09 & 1.02 & 0.32 \\
$\boldsymbol{p}$-nitrophenylacetic acid (PNPAA) at $\mathbf{1 0 0} \mathbf{~ p p m}$ & 5.34 & 1.04 & 0.29 \\
$\boldsymbol{p}$-nitrophenylacetic acid (PNPAA) at $\mathbf{1 5 0} \mathbf{~ p p m}$ & 5.82 & 1.05 & 0.25 \\
\hline
\end{tabular}

at concentration $150 \mathrm{ppm}$. The results are in agreement with (Talaat et al., 2014) reported that phenylalanine led to increase in level of growth hormones (IAA, GA 3 , total cytokinins) and low level of ABA. The increases in growth hormones levels could be attributed to the increase in their biosynthesis and/or decrease in their degradation. On the other hand, the reduction in ABA level could be due to the shift of the common precursor isopentenyl pyrophosphate to biosynthesis of cytokinins and/or gibberellins instead of ABA (Hopkins and Huner, 2004). Plant phenolic, as physiological regulator or chemical messenger, inhibit the IAA catabolism (dihydroxy B-ring flavonoids) or limit the IAA synthesis (monohydroxy B-ring flavonoids) (Mathesius, 2001).

\section{Recommendation:}

It could be recommended to spray cumin plants with $p$-nitrophenylacetic acid at 150 ppm to increase growth, fruits yield and volatile oil production as well as oil quality.

\section{REFERENCES}

Ahmed, M.A.; El-Mawla, A. and Beerhues, L. (2002). Benzoic acid biosynthesis in cell cultures of Hypericum and rosaemum. Planta, 214:727-733.

Amin, I.; Norazaidah, Y. and Hainida, K.I.E. (2006). Antioxidant activity and phenolic content of raw and blanched Amaranthus species. Food Chem., 94:47-52.

Bahadur, A.; Singh, D.P.; Sarma, B.K. and Singh, U.P. (2012). Foliar application of 1-phenylalanine and ferulic acids to pea 
plants: induced phenylalanine ammonialyase activity and resistance against Erysiphe pisi. Archives of Phytopathology and Plant Protection, 45(4): 398-403.

Bettaieb, R.I.; Karoui, J.I.; Sellami, H.I.; Bourgou, S.; Limam, F. and Marzouk, B. (2012). Effect of drought on biochemical composition and antioxidant activities of cumin (Cuminum cyminum L.) seeds. Industrial Crops and Products, 36:238245.

Beuerle, T. and Pichersky, E. (2002). Purification and characterization of benzoate:coenzyme a ligase from clarkia breweri. Arch. Biochem. Biophys.,400:258-264.

Boatright, J.; Negre, F.; Chen, X.; Kish, C.M.; Wood, B.; Peel, G.; Orlova, I.; Gang, D.; Rhodes, D. and Dudareva, N. (2004). Understanding in vivo benzenoid metabolism in petunia petal tissue. Plant Physiol., 135:1993-2011.

British Pharmacopeia (1963). Determination of Volatile Oil in Drugs. The Pharamaceutical Press London, UK, $1210 \mathrm{p}$.

Bunzen, J.N.; Guchard, J.; Labbe, P.; Sperinnet, P.J. and Trenchant, J. (1969). Practical Manual of Gas Chromatography. American Elsevier Publishing Co., Inc., New York, USA, $400 \mathrm{p}$.

Chang, C.; Yang, M.; Wen, H., and Chern, J. (2002). Estimation of total flavonoid content in propolis by two complementary colorimetric. Journal of Food and Drug Analysis, 10(3):178- 182.

Chen, Y.W.; Wu, S.W.; HO, K.K.; Lin, S.B.; Huang, C.Y. and Chen, C.N. (2008). Characterisation of Taiwanese propolis collected from different locations and seasons. J. Sci. Food Agric., 88(3):412419.

EL-Zefzafy, M.M.; Ismail, M.A.; Shahhat, R.S.Y. and Elsharkawy, E.R. (2016). Influence of foliar application with amino acids and citric acid on physiological and phytochemical responses of Artemisia abrotanum produced by in vitro culture. Biosci. Biotech. Res. Comm., 9(4):702711.

Finet, C. and Jaillais, Y. (2012). Auxology: when auxin meets plant evo-devo. Dev. Biol., 369:19-31.

Gamal El-Din, K.M.; Tarraf, A.Sh. and Balbaa, L. (1997). Physiological studies on the effect of some amino acids and micronutrients on growth and essential oil content in lemon grass. J. Agric. Sci., 22:4229-4241.

Gamal EL-Din. K.M. and Abd EL-Wahed, M.S.A. (2005). Effect of some amino acids on growth and essential oil content of chamomile Plant. Int. J. Agri. Biol., 7(3):376-380.

Giridhar, P.; Rajasekaran, T.; Nagarajan, S. and Ravishankar, G.A. (2004). Production of 2- hydroxyl-4methoxybenzaldehyde in roots of tissue culture raised and acclimatized plants of Decalepis hamiltonii Wight \& Arn., an endangered shrub endemic to southern India and evaluation of its performance vis-a-vis plants from natural habitat. Indian J. Exp. Biol., 42(1):106-110.

Habba, E.E.L. (2003). The role of amino acids ornithine and phenylalanine in growth, chemical constituents and alkaloidal contents in Datura innoxia Millennium. J. Agric. Sci., Mansoura Univ., 26:1261-1268.

Hamberger, B.; Ehlting, J.; Barbazuk, B. and Douglas, C.J. (2006). Comparative genomics of the shikimate pathway in Arabidopsis, Populus trichocarpa and Oryza sativa: shikimate pathway gene family structure and identification of candidates for missing links in phenylalanine biosynthesis. Recent Adv. Phytochem., 40-85-113.

Hashemian, N.; Pirbalouti, G.A.; Hashemi, M.; Golparvar, A. and Hamedi, B. (2013). Diversity in chemical 
composition and antibacterial activity of essential oil of cumin (Cuminum cyminum L.) diverse from northeast of Iran. J. Crop Sci., 7(8):1752-1760.

Herriman, K.M. and Weaver, L.M. (1999). The shikimate pathway. Annu. Rev. Plant Physiol. Plant Mol. Bio., 50:473-503.

Hoftman, E. (1967). Chromatography, $2^{\text {nd }}$ Ed. Reinhold Pulb. Corp., USA, pp. 208-515.

Hopkins, W.G.; Huner, N.P.A. (2004). Introduction to Plant Physiology, $3^{\text {rd }}$ Ed. John Wiley and Sons, Inc., USA, 560 p.

Horemans, S.; Van Onckelen, H.A.; Rudelsheim, P. and De Reef, J.A. (1984). Study of parameters involved in the determination of IAA and ABA in plant materials. Journal of Experimental Botany., 35(12):1832-1845.

Jensen, R.A. and Gu, W. (1996). Evolutionary recruitment of biochemically specialized subdivisions of family 1 within the protein superfamily of aminotransferases. J. Bacteriol., 178:2161-2171.

Jin, C.W.; Du, S.T.; Zhang, Y.S.; Tang, C.X. and Lin, X.Y. (2009). Atmospheric nitric oxide stimulates plant growth and improves the quality of spinach (Spinacia oleracea). Ann. Appl. Bio., 155:113-120.

Khalilzadeh, R.; Tajbakhsh, M. and Jalilian, J. (2012). Effect foliar application of bioorganic fertilizers and urea on yield and yield components characteristics of mung bean. International Journal of Agriculture Research and Review, 2:639-645.

Kneer, R.; Poulev, A.A.; Olesinski, A. and Raskin, I. (1999). Characterization of the elicitor-induced biosynthesis and secretion of genistein from roots of Lupinus Luteus L. J. Exp. Bot., 50:15531559.

Kundu, A.; Jawali, N. and Mitra, A. (2012). Shikimate pathway modulates the elicitor- stimulated accumulation of fragrant 2-hydroxy-4methoxybenzaldehyde in Hemidesmus indicus roots. Plant Physiol. Biochem., 56:104-108.

Lee, A.Y.; Stewart, J.D.; Clardy, J. and Ganem, B. (1995). New insight into the catalytic mechanism of chorismatemutases from structural studies. Chem. Biol., 2:195-203.

Maeda, H. and Dudareva, N. (2012). The shikimate pathway and aromatic amino acid biosynthesis in plants. Annu. Rev. Plant Biol., 63:73-105.

Maeda, H.; Shasany, A.K.; Schnepp, J.; Orlova, I.; Taguchi, G.; Cooper, B.R.; Rhodes, D.; Pichersky, E. and Dudareva, N. (2010). RNAI suppression of Arogenate Dehydratasel reveals that pathway in phenylalanine is synthesized predominantly via the arogenate in petunia petals. Plant Cell, 22:832-849.

Mathesius, U. (2001). Flavonoids induced in cells undergoing nodule organogenesis in white clover are regulators of auxin breakdown by Peroxidase. J. Exp. Bot., 52:419-26.

McCallum, J.A. and Walker, J.R.L. (1990). Phenolic biosynthesis during grain development in wheat: Change in phenylalanine ammonia-lyase activity and soluble phenolic content. Journal of Cereal Science., 11:35-49.

Orlova, L.; Marshall-Colona, A. and Schnepp. J. (2006). Reduction of benzenoid synthesis in petunia flowers reveals multiple pathways to benzoic acid and enhancement in auxin transport. Plant Cell, 18:3458-3475.

Oroojalian, F.; Keminshahi, K.R.; Azizi, M. and Bassami, M. (2010). Phytochemical composition of essential oils from three Apiaceae species and their antibacterial effects on food borne pathogens. Food Chemistry, 120(3):765-770.

Pascual, M.B.; El-Azaz, J.; De La Torre, F.N.; Cañas, R.A.; Avila, C. and Cánovas, F.M. (2016). Biosynthesis and metabolic fate of phenylalanine in 
conifers. Front Plant Sci., 7:1-13. https://doi.org/10.3389/fpls.2016.01030

Reham, M.S.; Khattab, M.E.; Ahmed, S.S. and Kandil, M.A.M. (2016). Influences of foliar spray with phenylalanine and nickel on growth, yield quality and chemical composition of genoveser basil plant. African Journal of Agricultural Research, 11(16):1398-1410.

Ribnicky, D.M.; Shulaev, V. and Raskin, I. (1998). Intermediates of salicylic acid biosynthesis. Plant Physiol., 118:565572.

Santner, A. and Estelle, M. (2009). Recent advances and emerging trends in plant hormone signaling. Nature, 459:10711078.

Schneider, E.A.; Kazakoff, C.W. and Wightman, F. (1985). Gas chromatography-mass spectrometry evidence for several endogenous auxins in pea seedling organs. Planta, 165:232241.

Small, D.K. and Morris, D.A. (1990). Promotion of elongation and acid in vertase activity in Phaseolus vulgaris L. internode segments by phenylacetic acid. Plant Growth Regual., 9:329-340.

Snedecor, G.W. and Cochran, W.G. (1980). Statistical Methods, $6^{\text {th }}$ Ed. Iowa State Univ. Press, Ames, Iowa, USA., 507.

Sugawara, S.; Mashiguchi, K.; Tanaka, K.; Hishiyama, S.; Sakai, T.; Hanada, K.; Kinoshita-Tsujimura, K.; Yu, H.; Dai, X. and Takebayashi, Y. (2015). Distinct characteristics of indole-3-acetic acid and phenylacetic acid, two common auxins in plants. Plant Cell Physiol., 56:1641-1654.

Takahashi, M. and Morikawa, H. (2014). Nitrogen dioxide is a positive regulator of plant growth. Plant Signaling and Behavior, 9:1-4. http://dx.doi.org/ $10.4161 / \mathrm{psb} .28033$

Talaat, J.M.; Khattab, H.L. and Ahmed, A.M. (2014). Changes in growth hormones levels and essential oil content of Ammi visnaga L. plants treated with some bioregulators. Saudi Journal of Biological Sciences, 21(4):355-365.

Talaat, I.M. and Youssef, A.A. (2002). The role of amino acids lysine and ornithine in growth and chemical constituents of basil plants. Egyptian J. Appl. Sci., 17:83-95.

Taylor, D.C. and Wightman, F. (1987). Metabolism of D, L-chlorophenylalanines by phenylalanine aminotransferase isozymes purified from bushbean shoots. Phytochemistry, 26:1279-1288.

Tzin, V.; Malitsky, S. and Aharoni, A. and Galili, G. (2009). Expression of a bacterial bi-functional chorismate mutase/prephenate dehydratase modulates primary and secondary metabolism associated with aromatic amino acids in Arabidopsis. Plant J., 60:156-167.

Wang, J.P.; Naik, P.P; Chen, H.C; Shi, R.; Lin, C.Y.; Liu J.; Shuford, C.M.; Li, Q.; Sun, Y.H.; Tunlaya-Anukit S.; Williams, C.M.; Muddiman, D.C.; Ducoste, J.J.; Sederoff, R.R. and Chiang, V.L. (2014). Complete proteomic based enzyme reaction and inhibition kinetics reveal how monolignol biosynthetic enzyme families affect metabolic flux and lignin in Populus trichocarpa. Plant Cell, 26:894-914.

Yoo, H.; Widhalm, J.R.; Qian, Y.; Maeda, H.; Cooper, B.R.; Jannasch, A.S.; Gonda, I.; Lewinsohn, E.; Rhodes, D. and Dudareva, N. (2013). An alternative pathway contributes to phenylalanine biosynthesis in plants via a cytosolic tyrosine: phenylpyruvate aminotransferase, Nat. Commun., 4:2833.

Zucker, M. (1965). Induction of phenylalanine deaminase by light and its relation to chlorogenic acid synthesis in potato tuber tissue. Plant Physiology, 40:779-784. 


\section{تحفيز النمو وإنتاج الزيت في نبات الكمون}

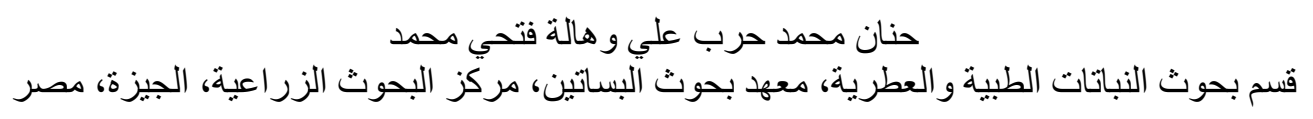

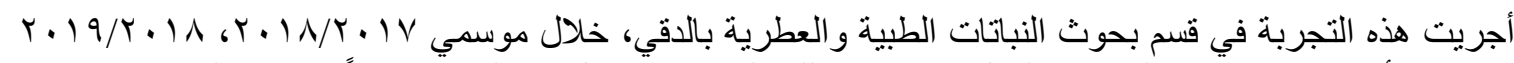

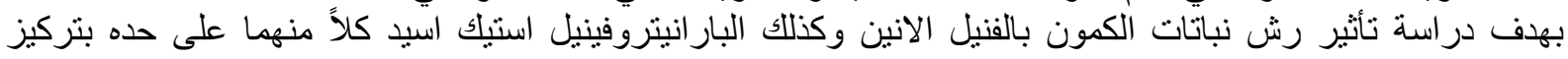

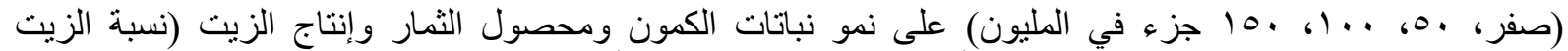

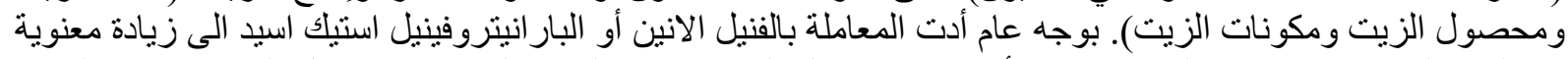

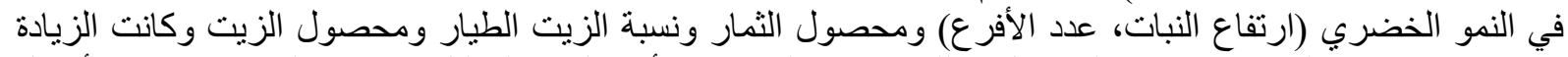

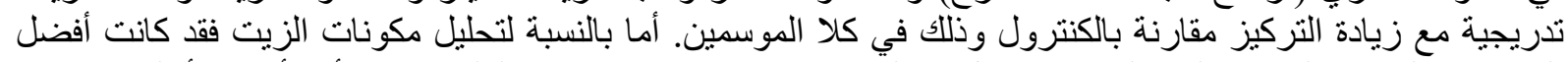

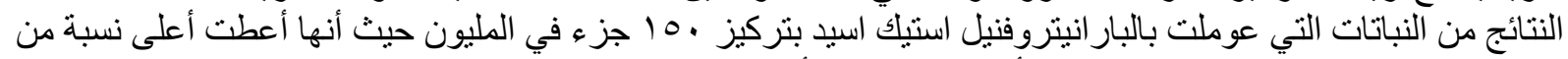

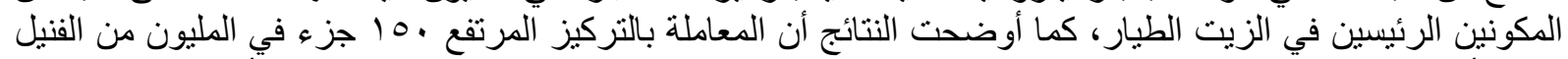

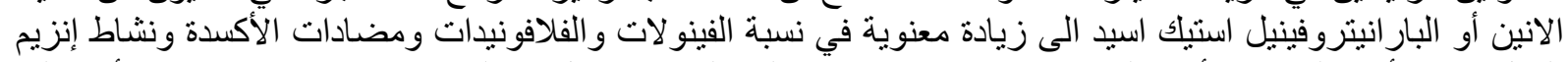

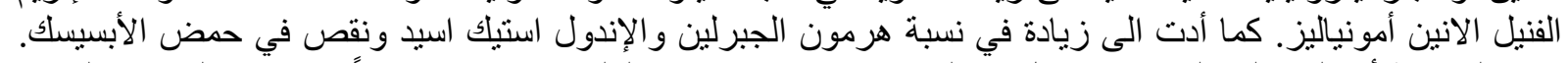

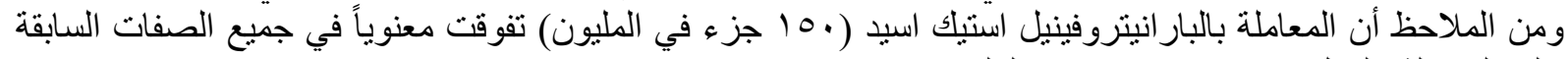

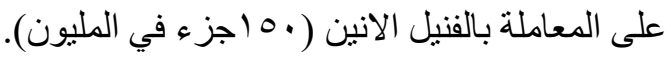

